\title{
Engineering students' instrumental approaches to mathematics; some positive characteristics
}

\author{
Ragnhild Johanne Rensaa \\ Faculty of Engineering Science and Technology, UiT the Arctic University of Norway, Narvik, Norway \\ For correspondence: ragnhild.rensaa@uit.no
}

\begin{abstract}
The present paper presents three deliberately chosen mathematical episodes observed in a class of engineering students taking a basic calculus course. By drawing on analyses of instrumental and relational learning strategies, the episodes are shown to illustrate instrumental approaches indicated by the students. The paper discusses positive characteristics about these approaches while further data collections shed light on reasons why such approaches were preferred. Results reveal some positive characteristics, suggesting that instrumental strategies may serve as valuable parts of the learning environment in engineering educations. If students are motivated by instrumental approaches, then utilizing positive aspects about them may be an important starting point in teaching. Awareness of this may provide useful in stimulating for relational learning based on instrumental profits.
\end{abstract}

Keywords: Engineering students, instrumental learning strategies, mathematics, setting

\section{Introduction}

The mathematics discipline has a central role in an engineering education since it provides both analytic skills and is the basis on which more engineering specific disciplines are built. Still, engineering students do not necessarily understand the need to study mathematics, as pointed out by Sazhin (1998), they do not know how mathematical demanding their studies are (Harris, Black, Hernandez-Martinez, Pepin, \& Williams, 2015), and their interests lie primarily in disciplines other than the mathematics itself (Kümmerer, 2001). In these settings, it becomes important to seek understanding of what is going on in the mathematics classroom of engineering students, seek explanations to mathematical episodes and try to discover what raises certain mathematical behaviours.

Within education, there is a large focus on providing teaching methods and learning environment for the students to gain deeper understanding of the disciplines. In mathematics, methods and procedures - the carrying out of processes - are important to accomplish a task, but knowing why a formula works and how it has been developed is regarded as vital for deeper understanding. Thus, students need to know task solving procedures, but placed in a system - what is known as relational thinking. Being able to combine relational and instrumental understanding has been used to characterise a successful mathematics student (Hiebert, 1986; Skemp, 1987). However, along with this emphasis on positive aspects on relational knowledge, instrumental learning has got somewhat negative timbres, at least if being a main preference by students. Students should not concentrate on routine tasks, should not mainly draw on readymade formulas and should not strive to find patterns from previous tasks and examples to solve new ones. The present paper investigates three deliberately chosen episodes in which exactly these approaches were observed in a freshmenengineering classroom. These episodes could then be deemed as illustrating what is regarded as not 
optimal mathematical behaviours. Yet, are these approaches mainly unsatisfactory, or are there positive aspects about them which justify their existence? This is what I want to dig deeper into by analysing the episodes more closely, but also by interviewing some students and the teacher in class. The questions that guide this research are: What positive characteristics are there to some episodes of instrumental type observed among freshmen-engineering students in a mathematics classroom? How may students' and the teacher's statements contribute to substantiate such approaches?

The observed episodes illustrate approaches related to an instrumental learning strategy. Thus, to set the ground for the paper, we need to define this strategy. The next section does this, along with the rationale for learning and educational setting. Vital here are the freshman engineering students, thus theories about their strategies are also included. Next, arrangements for the calculus course along with the methodology are presented before providing analysis and results.

\section{Theoretical framework}

Investigations of learning strategies by students require a clarification of what is meant by learning. Skemp $(1978,1979 b)$ distinguishes between instrumental and relational learning. According to him, relational learning is not dependent upon subject matter, it is deep and about building of schemas for conceptual structures. A person's schema is a cognitive map that connects mathematical concepts to each other by integrating knowledge from past experiences to one's own reflections. In Skemps model, a schema exists in its own right, while Piaget and Inhelder (1969) connect it to a structure of actions as these, by repetition, are generalized to similar circumstances. Relational learning is for a student motivated by an interior pleasure of gaining relational understanding, which according to Skemp is to know both the motive and the structure of a concept. Instrumental understanding, on the other hand, is a type of reasoning based on mastering rules or procedures without asking 'why?'. Skemp defines this as "recognizing a task as one of a particular class for which one already knows a rule" (Skemp, 1979b, p. 259). Instrumental learning is superficial, rule based and connected to a particular class of tasks to be solved. Instrumentalism is a learning strategy that produces instrumental understanding. Mellin-Olsen (1981) brings forth that motivations for instrumental knowledge may vary. It may be both intrinsic motivated by an S-rationale for learning and extrinsic motivated by an I-rationale for learning. In the latter case, motivation for learning is driven by a student finding little use of what she studies except for being something that she is forced to learn as part of her education, i.e. without a deeper structure in her learning process. An S-rationale for learning, however, may be seen as a symptom of some deeper structure. In this case, the social importance of learning the discipline is clear to the learner and this, together with her self-concept and own reading of the setting, forms her strategies for learning. As stated by Mellin-Olsen; "It is the rationale for learning evoked in the pupil by a synthesis of his self-concept, his cognition of school and schooling, and his concept of what is significant knowledge and a valuable future, as developed in his social setting“ (1981, p. 357).Thus, an S-rationale for learning may have both an interior and an exterior meaning. The interior part is connected to the student herself; which emphases she has in her learning processes. The exterior part is about the expectations of learning imposed on students by the context. The analyses of episodes in the present paper will draw on S- and I-rationales for learning.

A similar distinction between types of knowledge as introduced by Skemp has been given by Hiebert and Lefevre (1986), who define conceptual and procedural knowledge of mathematics. Conceptual knowledge is "knowledge that is rich in relationships" (ibid, p. 6), thus cannot exist in isolation. Increase of such knowledge takes place when unrelated items eventually are seen as related in some way and when relationships between existing knowledge and new information are created. In contrast to this, procedural knowledge involves primarily sequential relationships or "step-by-step instructions that prescribe how to complete tasks" (Hiebert \& Lefevre, 1986, p. 6). Procedural mathematical knowledge thus embraces two types of information; familiarity with symbols on the 
one hand, and familiarity with rules, or procedures, for solving classes of tasks, on the other hand. Meaningful knowledge of procedures and concepts is obtained when interrelating the categories and realise how one may lead to the other (Baroody, Feil, \& Johnson, 2007; Rittle-Johnson, Schneider, \& Star, 2015; Skemp, 1978). By linking the two, learning of procedures and facts may be easier. Errors may be fewer, computational shortcuts may be familiar and forgetting may be reduced (Baroody et al., 2007). Relations between conceptual and procedural knowledge are often bidirectional, as improvements in one type often supports improvements in the other (Rittle-Johnson et al., 2015). It is, however, important to define and explain their meaning when using the notions of conceptual and procedural knowledge. This is because research has shown that professionals in undergraduate mathematics education may put rather different meanings into these notions, at a risk of reading results differently according to own interpretations (Rensaa \& Vos, 2017). To avoid ambiguity in this paper, I will stick to Skemp's terminology of relational and instrumental knowledge.

In his grounded theory approach to explain engineering students' conceptions of understanding in mathematics learning, Khiat (2010) develops three types of understanding in addition to relational and instrumental. These are functional, associational and disciplinary understanding which, according to Khiat, are uniquely present in engineering mathematics learning. Functional understanding is the ability that these students have to understand the function of a formula or procedure; their interpretation of it. To some extent, functional understanding may be considered as a part of Skemp's relational understanding since this type of understanding includes understanding the uses of concepts. In the third episode of the present paper, the students' interest in a certain formula may indicate an instance of functional understanding as searching for the meaning of this formula. This, however, is only at a superficial level as their main motivation is to find a rule to use in other cases. Further, Khiat designate associational understanding to engineering students' ability to utilize the mathematical formulas and convert these into engineering forms in order to solve problems. It differs from Skemp's relational understanding as Skemp refers to relations between mathematical concepts while associational understanding is about relating mathematics and engineering problems. Additionally, engineering students need to relate their understanding to engineering concepts or theories. Knowing such engineering disciplines - which Khiat denotes as disciplinary understanding - may be important in motivating for and learning of engineering mathematics. Disciplinary understanding is, according to Khiat, needed in order for students to achieve associational understanding. It is, however, neither conceptual nor procedural in nature as it focuses on the engineering concepts and theories, not the mathematics.

Learning mathematics is seen as a student coming to new knowledge, and this knowledge present itself in a pedagogic situation. In this situation, students need to become able to relate mathematical features both to one another but also to the wider social and educational context. The role of mathematics in the wider field of engineering disciplines as well as the work as engineers is important and interpreting learning strategies as a contextualized activity is relevant. In this, it becomes important to clarify the meaning of context or setting. Wedege (1999) distinguishes between task-context and situation context, in which the former focus on whether the different teaching materials are relating to a real-life context. Task context is relevant in the third episode in the present paper. Situation context is more about the context of knowing, learning and using mathematics in settings like school, workplace and everyday life, and about the context of the mathematics education itself, comprising educational systems and policies. Solving the same practical task but in different classes - like in a mathematics class and a social studies class - may serve as an example of different situation contexts (Wedege, 1999). In the present paper, the main setting is an engineering education.

Mathematics is an important subject in engineering educations, a subject on which professional courses are built. "Mathematics is an important subject in itself and plays a crucial role not only during an engineering course but also by providing a solid foundation for the practice of the 
engineering profession" (Varsavsky, 1995, p. 344). This, however, is often not realized by engineering students before they enrol for their degree. Harris and colleagues was surprised to uncover that very few 'becoming engineers' in their study actually knew how mathematically demanding their studies would be (Harris et al., 2015). Some of these students even would have chosen another course if they had known. Students' obstacles in learning of undergraduate mathematics is repeatedly discussed by researcher. Kashefi and colleagues (Kashefi, Ismail, \& Yusof, 2012) refer a list of obstacles such as difficulties with interpreting concepts, ways of transferring mathematics and students learning styles, but also more doing aspects like problems with absorbing complex ideas within a short time frame, poor problem solving skills and lack of competence in algebraic manipulations. The Kashefi findings show that additional problems for engineering mathematics is imagining and sketching in 3dimensions, thus being another obstacle of learning. To many engineering students, mathematics is considered to cause most problems in their field of study. Harris and colleagues (2015) conclude that a reason is that the transfer of mathematics to engineering seems problematic to students and may make them feel insecure about the subject. Mathematics that is disembedded from use makes the 'usevalue' lost. Khiat's investigation of engineering students' conceptions of understanding in mathematics learning (2010) highlights a related challenge. The students in his study generally focus on gaining procedural and associational understanding of mathematics and Khiat concludes this to be sufficient for engineering students as conceptual understanding is of no academic value. This is since proving or justifying the formulae is not needed in examinations and in future jobs as engineers. Thus, most students do not pursue conceptual understanding. A result similar to Khiat's is found as part of a larger study by Engelbrecht, Bergsten and Kågesten (2012), which investigates two groups of engineering students' opinions about mathematics. The inquiries show that these students view mathematics as instrumental while the relational approaches are relevant outside mathematics.

\section{The research methodology}

The present study is a descriptive case study as it concerns analysis and explanations of a set of three episodes. Stake (1995) defines three types of case studies; intrinsic, instrumental and collective case studies. The second one aims at getting insight into a specific issue or illuminate a hypothesis, while the third one comprises investigations of a number of different cases. The present research, however, relates to the intrinsic case study. Such studies are undertaken to gain better understanding of a particular case - not because it is unique or typical - but because it is interesting in itself. The set of three episodes to be presented is most certainly not rare or unique to the class or to engineering students' mathematical behaviours. Nevertheless, they evoked my interest, thus found worthy to investigate.

\section{The mathematics course in short}

The mathematics course was given to engineering students in their first year of studies at a university college in Norway. It contained classical calculus topics like properties about functions, integration, differential equations and complex numbers. Additionally, a short introduction to linear algebra was included. Since the linear algebra part was small and none of the episodes relates to this, the course is named "calculus course". The textbook used in the course was Adams (2006). Estimated workload was 10 credits from a total of 60 credits annually. The organization of the course was traditional, with plenary lectures followed by task solving sessions. There were about 100 students in class. During the task solving sessions the students were split between two classrooms and worked in groups or individually with tasks. A tutor provided assistance if needed. The less traditional part of the schedule was that the course was taught intensively for a week, followed by a week with other disciplines and a third week called a 'study week'. This three-week-cycle was repeated all through the semester and ended with a final, summative exam in the course. At the end of each study week and before entering a new 'mathematics week', the students were encouraged to take a mini-test to summarize the previous content. 
The teaching of mathematics to engineering students

Teaching mathematics to engineering students is not an easy task. Kashefi and colleagues (2012) bring forward a list of obstacles based on previous researchers' findings. Among these are knowing how to coordinate multiple procedures, mathematical abilities and ability to solve none-routine questions, but also challenges as mathematics is not a priority subject to engineering students despite the list of required mathematical abilities needed for an engineer being rather long. The Kashefi study adds lack of skills and background knowledge together with a students' practise of memorising concepts to this list (2012). Mustoe describes the engineering mathematics lecturer as "the pig in the middle" (Mustoe, 2002). He meets expectations from teachers in specialized disciplines that the students should be introduced to a variety of mathematical concepts and tools to be able to cope with mathematical demands in their modules. The students themselves often just want to be taught to pass the exam, while the mathematics teacher hopes to contribute to a coherent understanding of the discipline. Such teaching challenges may, according to Kümmerer (2001), be met by different approaches. One style may be the 'workman approach' where mathematics is apprehended as a machine consisting of rules which, when being followed, automatically gives the correct answer to a problem. Another style is a 'gentle approach' to the discipline (Kümmerer, 2001). Mathematics is then made user-friendly by including selected heuristic explanations rather than formalistic proofs, producing neat results. Kümmerer suggests instead that 'The optimum might be to develop an integrated course that teaches mathematics in combination with the intended applications' (2001, p. 323). Other researchers stress this aspect of teaching too, connecting mathematics to applications. Steen (2001) emphasizes that mathematics taught in a context that reflects students' career goals is learned more readily. The same is happening if examples used in mathematics resonate with those appearing in professional courses. Khiat (2010) states that 'In order to utilise mathematics in engineering scenarios, students have to achieve disciplinary understanding that give meanings to the functions of the mathematical concepts they have learned' (p. 1482). Harris and colleagues (2015) underline that whichever way one teaches mathematics to engineering students some will have problems, but a decontextualisation may disembed mathematics from it use.

The teacher responsible for the present mathematics course did strive to meet a use-value-expectation by including engineering related problems in the calculus course. He often brought forward tasks referring to real world situations during lectures, tasks that needed translation to mathematics before drawing on methods to achieve mathematical results. This would usually be accompanied by interpretations of the results, following a process of mathematical modelling (Blomhøj \& Jensen, 2003) The sheet of tasks that each week was distributed to the students in task solving sessions did usually contain a selection of modelling problems. In addition, similar task did frequently appear in previous final exams in the course, implying a student focus on such tasks. As for the lectures in general, the teacher was a very likable one and the students frequently appreciated his teaching by nominating him for the award given by students to the best teacher of the university college. He sought to engage the students during lectures by asking questions and having a dialog. He succeeded with this approach, mainly due to his informal and humoristic manner of teaching. He also picked up comments from students about alternative solving strategies and discussed these in class.

The researcher as tutor role

The episodes of interest in the present paper came about during task solving sessions of the mathematics course. My original intention was to be a silent observer in class, interrupting as little as possible to the course implementation. However, experiences from a pilot study were that an observer in class became artificial to both the engineering students and me. This caused my role in the main study to change to a subordinated tutor for the students in one of the classrooms set out for the task solving sessions. My role was to be a researcher and tutor for the students in one of the two classrooms set out for task solving sessions. The students were informed about the research project and knew that data was collected. I brought with me predetermined sets of tasks to these sessions, 
tasks that had been selected by the responsible teacher. I was not to influence the scheme, but provide help if needed. This was decided to reduce interference with the mathematics course that I was investigating. The role as tutor rather than an artificial observer made the setting in class more normal. I was helping out as is expected of any teacher in a problem-solving class. Also, I could inquire into the students' arguments by asking questions when providing help. In order to appear natural, I only made short notes about observations during class and carefully logged events after class. Among a number of episodes that occurred, three are discussed in the present paper. These episodes do illustrate some typical - but not supreme - task solving approaches in the calculus course. They are selected because they were driven by an instrumental approach accompanied by students' behaviours and arguments asserting this to be sufficient.

To get more insight into the learning environment, additional interviews were conducted with both students and the teacher in class. The students were selected based on observations and two mini-test results to get a spread in qualifications. A number of shorter interviews with the teacher were done in addition to two longer ones. All the interviews were semi-structured.

\section{Interpretations of learning strategies}

Analyses of episodes are done by utilizing Skemp's specification of relational and instrumental learning (Skemp, 1979a), with the split of instrumentalism as given by Mellin-Olsen (1981). Interpretations are as follows:

- Relational learning is deduced when an argument seeks to connect concepts and construct conceptual relations, and when the development of a process or deduction of a method is considered just as important as the process or method itself.

- Instrumental learning is interpreted whenever an argument placed emphasis on obtaining a right answer and on using rules by manipulating symbols, and not so much on the concepts involved. This strategy may be split into two forms (Mellin-Olsen, 1981). An I-rationale for learning is interpreted when a statement indicates satisfaction with demonstrating some knowledge in order to obtain correct answers. This includes imitating related solution procedures without showing interest in the origin of this procedure. An S-rationale for learning is read when a statement indicates more to the learning strategy than just an external acknowledgement of obtaining the right answer. It may refer to an inner motivation to learn, in which mathematical arguments are found valuable in a wider perspective than just for the school discipline.

Additional data given by students and the teachers in interviews are referring to rationales for learning more generally. Thus, these data are interpreted in a meta-perspective by drawing on the above refinements.

\section{Methodological concerns}

A recurring concern about the data collection techniques is whether the results can be trusted. In the present research, trustworthiness is pursued by the variety of data collected and by use of more than one source for information. This may result in a greater confidence in findings (Bryman, 2004, p. 275). My role as tutor in class did imply a familiarity with students that made the classroom setting realistic with natural behaviours and hopefully non-artificial answers. However, the role as tutor is also a point of concern. I was a participant observer which is recognized as one that possibly can influence the results and conclusions of an investigation. It may also create a problem of distancing, and subjectivity is unavoidably an important aspect. Still, one can find "objectivity in transcending rather than rejecting apparent subjectivity" (Mason, 1998, p. 360), and I tried to bear my subjectivity in mind throughout all interpretations. The intentions were the same as Jaworski (1994), who eventually felt comfortable with a role in class where extensive discussions with students were included and took such an involvement into consideration when subsequently interpreting the data. Incorporated in the 
role as tutor, and not as teacher, was that I had no decision-making authority about the course content. The actual meaning of this I grasped during the development of the second episode, where the student in focus changed strategy after having consulted the responsible teacher. It made me realize that it was not my course, which helped me to position myself more as an outsider. However, I learned that being a tutor and a researcher at the same time is challenging. It was hard to get time to make notes about events when around 40 students solved tasks and asked for help. Busy sessions often resulted in the elapse of long time periods before there was time for me to log events. The tutor role enforced the teaching focus to be given higher priority than the research.

As to the validity of the research findings, respondent validation is a way of convincing others about a good match between observations and their interpretations. In the present research project, it was not possible to return to the students with interpretations. Such processes have to be carried out in near proximity to an event for the students to remember it, and that would have interfered with the "normal" tutor-student relationship; a disturbance of context (Gallagher, 1995). Towards the teacher, however, observations and interpretations were often put forth - in order to evoke his response. The teacher was an important discussion partner to get supplementary information and reactions to findings.

\section{Analysis and results}

\section{Episodes}

The first episode

The first episode took place in the first task solving session. Each student got a sheet of tasks selected by the teacher. This sheet contained a list of exercises to be completed from the textbook, but additionally some supplementary tasks formulated on the paper. I observed a male student struggling with the problems from the textbook and tried to give him some hints as to where to start. But, when I returned later, he had given up the textbook and started working with the additional tasks instead. The task he had started asked the students to find the exact value of $x$ when $\arccos x+\frac{\pi}{6}=\arctan 2$. He was more successful with this task, and explained to me what he had done. I agreed and only needed to help him finding the exact values of some angles before his solution was finished. The teacher had gone through a similar problem during lectures, and the student solved the task by following this procedure, putting up a triangle as a supporting figure (see Appendix 1 for a suggested solution). He immediately engaged in another and a third similar task which he also managed to solve. He obviously found motivation to do this type of task instead of the ones he struggled with previously.

After class I asked the responsible teacher why such trigonometric tasks were included since they were not part of the textbook's tasks. He explained it like follows:

They represent a straight forward solution process. When you have solved one of these tasks, you can deal with all related ones. Even rather weak students can learn the method and manage to solve such tasks on tests. It gives them a feeling of being able to handle problems that look difficult. It is good for their self-image.

The observed student did display such a behaviour. He did not manage to start off the exercises in the textbook, but handled equations with inverse trigonometric functions with few problems. His continuation in doing all similar tasks indicated that these tasks evoked some feeling of succeed, which may increase self-concept. This indicates fractions of S-rationale, increasing self-concept and finding some significance in continuing such tasks more than just doing 'boring calculations'. However, the student's rationale may as well have been 'show off' intentions, demonstrating that he mastered to solve such apparent complicated equations. As a result, the evoked rationale for learning 
by solving such tasks is instrumental, focused on processes rather than relating to theories about trigonometric functions.

This episode illustrates a main issue when it comes to learning of mathematics; the concern about selfconfidence. Confidence and self-motivation are important factors in students' success (Varsavsky, 2010). When students are new to the educational system like the present students were, they may easily be overwhelmed by a feeling that they cannot master the discipline. The teacher's comment about arcus-tasks being included to improve self-image for the weak students shows that such considerations were made. Low self-esteem may be due to weak mathematical background, making it difficult to connect new knowledge to what has been already learned. Lack of background knowledge is a main concern with lecturers in engineering mathematics (Kashefi et al., 2012). There is also a mismatch between expected and realistic abilities of freshmen-engineering students (Mustoe, 2002). The teacher of the present calculus course emphasises the importance of arcus-tasks as building selfconfidence and one way of meeting challenges in transfer between school systems.

\section{The second episode}

The second event did also occur early in the mathematics course. A rather bright student asked me how to integrate $\sin ^{2} x$. He was an adult that had completed secondary school many years ago and had probably forgotten how to deal with this type of task. The student seemed rather puzzled about my suggestion of writing $\sin ^{2} x$ as $\sin x \sin x$ and integrating twice by parts, and concluded that he needed to reflect upon this solution. Then, when we met in the next problem-solving session, he told me that he had consulted the teacher about the integral argument. He had asked if this was likely to be given in the final exam, and the teacher had said no. This was since the book of formulas that the engineering students can bring to their exams contain the ready-made solution to $\int \sin ^{2} x d x$. "But aren't you interested in understanding why the integral of $\sin ^{2} x d x$ equals $\frac{1}{2} x-\frac{1}{4} \sin 2 x+C$ ", I asked. "Honestly, no", the student said, "there are so many things for me to learn, I have to concentrate on stuff that I will be tested in".

This student originally strived for relational understanding as seeking to know how to develop a process for solving the given integral. This argumentation, however, was found difficult, thus he contacted the teacher in class. By not pursuing the $\sin x \sin x$-argument, the student chose to put aside a relational understanding, showing a preference to an instrumental approach. The teacher's statement about readymade formulas made the student's final approach be of an I-rationale for learning - focusing on obtaining a correct answer. This approach was justified by reference to what was relevant for the final exam. Still, the student's eager to search for a solution - even by a shortcut indicates a motivation for wanting to know how to obtain a solution.

After class I discussed this episode with the teacher and asked about reasons for his response to the student about how to find $\int \sin ^{2} x d x$ :

There is no room for digging deeper into methods for integration, hesaid. Since the mathematics course has such a vast content and other teachers expect the students to know about a broad aspect of mathematical themes when entering engineering specific disciplines, we have to rush through some parts. And since the book of formulas gives readymade integral formulas, it is timesaving to refer to these formulas. Then we can devote more time to other parts.

A number of factors in the educational context are pinpointed to influence the course content by this statement: Time constraints, expectations of teachers in professional related courses and the use of remedies. The teacher of the present calculus course had chosen to meet this challenge by drawing on readymade formulas whenever possible. His statement indicates that if a formula is give in the book 
of formulas, then it can be used directly without understanding its origin. In such cases, relational understanding is not in focus. It enhances instrumental learning, an I-rational for learning, with a main goal about obtaining a correct answer.

\section{The third episode}

The third episode took place towards the end of the calculus course. Throughout the course, the students were given a variety of modelling tasks related to the mathematical themes they were addressing. Such tasks often include sizes that change with time. Thus, derived equations do often depend indirectly upon a time variable. A typical but simple example is found in the textbook (Adams, 2006, p.211), see Figure 1.

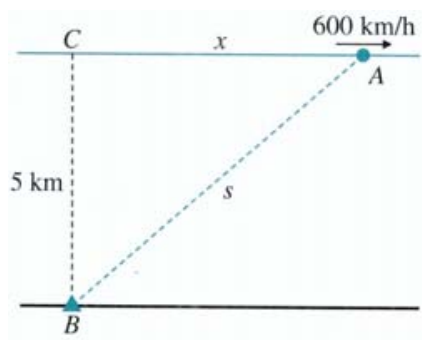
the distance between the aircraft and a radio beacon increasing $1 \mathrm{~min}$ after the aircraft passes $5 \mathrm{~km}$ directly above the beacon?

Figure 1. Example from Adams' book

The illustration in Figure 1 gives, by Pythagoras' theorem, that $s^{2}=x^{2}+5^{2}$. This equation needs to be differentiated implicitly with respect to the time variable since the distances change with time and the rate of change horizontally is known. Thus,

$$
2 s \frac{d s}{d t}=2 x \frac{d x}{d t} \Leftrightarrow s \frac{d s}{d t}=x \frac{d x}{d t}
$$

The rest of the solution is straight forward ((Adams, 2006, p. 211) may be consulted). The argument of interest here is $\left(^{*}\right)$, where $s \frac{d s}{d t}=x \frac{d x}{d t}$. This, or similar relations, occurred in a number of solution manuals that were available to the students. Near the end of the calculus course, the students started to prepare for the final exam by revising the solution manuals. During this period, two different students - on two separate occasions - asked me if the relation $\left(^{*}\right)$ represented a rule that could be used in all time dependent tasks. On the first occasion I did not grasp the meaning of the question and asked the student to explain to what he was referring: "I have been reading many of the solution manuals now", he said, "and the relation $x \frac{d x}{d t}=y \frac{d y}{d t}$ (the student grabbed a pencil and wrote the relation on a piece of paper) or something of that sort occurs often in practical tasks. Is this a rule that I can use in general?" Implicit differentiation had been explained many times during the mathematics course, but the two students had read the repeated relation as a rule.

This episode illustrates a learning strategy where particular problems are regarded as rule based. The motivation for solving the tasks was not to understand how to derive relations like ${ }^{*}$ ), rather to demonstrate some knowledge by using a 'universally given rule'. This view is related to Kümmerer's workman approach (2001) in which applying a set of rules somewhat automatically produces the correct answer. The students had got the idea of a rule by reading solution manuals and finding commonalities, and then sought an extrinsic verification of the rule to be true. This indicates learning with an instrumental aim with an I-rationale for learning. Nevertheless, some relational characteristics may be read as the students' search for a pattern between solving procedures in solution manuals indicates a want to discover relations between time dependent tasks. 


\section{Interviews}

When asking the students about their opinion of modelling tasks, which the example in Episode 3 is an example of, one student emphasized their connection to realistic situations:

S1 (student): I actually do like such tasks.

I (interviewer): Why?

S1: Because then it is easier to sort out what to do, and...usually they are more related to the real world than the pure number tasks...... You have to think more independently and be able to put yourself into the setting of the real world...... in order to solve such tasks one has to understand why one is doing this.

The statement shows that the student interprets these types of tasks to have social importance in addition to school relevance, thus valuable in a wider perspective. The student points to a 'use-value' of mathematics as defined by Harris and colleagues (2015), in which he needs to identify relevance to the social activity of performing an engineering profession. Thus, he refers to the 'why' as finding the connection between mathematics and the real world. This differs from relational understanding as defined by Skemp (1978) since it relates mathematics to practical situations while Skemp defines it as relationships between mathematical concepts. Steen (2001) asserts that mathematics taught in context of use is learned more readily.

The second interviewed student stressed modelling tasks as important with a slightly different argument:

S2: In the specialized courses we probably most of all have to solve such type of tasks, and then it is important that we do this in mathematics first.

The statement puts focus on the solving process itself, which may be regarded as an instrumental value. The student perceives dealing with these kinds of mathematical tasks as an important foundation for similar problems occurring in professional disciplines of his engineering education. According to Khiat (2010), disciplinary understanding, as students' understanding of engineering concepts, is uniquely present in engineering students' learning of mathematics, and the students' statement brings up exactly this relevance. It underlines the service role mathematics seems to have in engineering educations, also emphasized by researchers (e.g. Steen, 2001). Students with such reading of mathematics may put less emphasis on deeper mathematical arguments and seek for algorithms to solve specific modelling problems, but this depends upon types of tasks both in mathematics and in professional courses.

Not all students expressed an appreciation of modelling tasks connected to realistic problems. A third interviewed student explained:

S3: To me it has no significance that such tasks are from real life. They could as well have been about mathematical objects. I like it best when the tasks are arranged. They may very well involve complicated calculations, but when the tasks are arranged they are still easier.

This student rejects a social importance of mathematics as connected to applications and other disciplines. Instead, she emphasizes the instrumental value of calculations and expresses satisfaction with being able to tackle even complicated calculations. This is more associated with an I-rationale for learning in which obtaining answers is regarded to be a main achievement. Nevertheless, this student signalizes a feeling of satisfaction if being able to master complicated calculations. This relates to what was observed in the first episode. It indicates fractions of S-rationale as increasing selfconcept in accomplishing such calculations. The student is not alone in displaying preference to such strategies, but the problem is particularly relevant to engineering students since mathematics often is apprehended as a routine practice for their profession (Steen, 2001). 
Discussions of modelling tasks led the interviews into relevance of lecture notes, as these were utilized in task solutions. One student explained:

S1: If I am stuck in a task and we have done a similar type of task during lectures, then I look it up in the lecture notes. I prefer the lecture notes because the textbook uses wordings and symbols that I do not understand. The teacher uses symbols and expressions that are easier to grasp.

This student signalizes a want to understand the solution process, but has experienced the formalism of the textbook to create obstacles. Thus, he prefers to use the lecture notes as his task solving strategy since the mathematics is presented in more familiar terms there. This approach may originate in an inner motivation for gaining understanding of the solution process and seeing this as valuable - an Srationale for learning. Nevertheless, avoiding formalism is more related to an I-rationale. This is since grasping mathematical symbols and formalism is an important competence in mathematics, and avoiding these may indicate preference to demonstrate some knowledge to obtain a correct answer. Students have problems with decoding symbols because they read the symbols themselves without trying to grasp the meaning of them (Pimm, 1987), and the preference to lecture notes in mathematics is documented (Anthony, 2000; Bergsten, 2011; Randahl, 2012; Rensaa, 2014). Notes are often shorter and straighter to the point, which is appreciated by many students. Notes may also skip some theoretical arguments - which is in line with the following student's statement:

S3: All engineers have to study mathematics. But not so much theory - I mean definitions and theorems. I cannot see how it can help us to understand....mathematics.

To this student, understanding is not about mathematical theory and connections to why procedures work. She dismisses by this an important characteristic with relational learning. At the same time, however, she expresses an awareness that mathematics is a necessary part of engineering studies. Such consciousness is not clear to all engineering students, as shown by Harris and colleagues (2015). In their study, the researchers were surprised to learn that a great number of the engineering students in focus were unaware of how mathematically-demanding their studies would be. The quoted student emphasise the importance of mathematics in her study, but refers to the relevance of the subject as something else than theoretical arguments. This may indicate more of an instrumental view, regarding mathematics more as a set of concepts without basing these in theory.

\section{Interview with the teacher}

Two interviews with the teacher in the course were implemented; one at the beginning of the course and one in the middle of the semester. A concern with the teacher was his experience of the weak mathematical background of many freshmen-engineering students, making it difficult to include extended theoretical arguments in the calculus course. This, he explained, was a reason for putting emphasis on illustrative arguments rather than theoretical ones:

$\mathrm{T}$ (teacher): It is the figurative representation I am chasing - because that is quickest to get into their head. By this, they see the concept in another connection. Because if you only give them a text then... they do not understand... If you give them a definition with all its conditions and other things, then it simply becomes too much for them to see the point.

The teacher initially emphasizes relational learning as connecting new concepts to figurative representations to enrich the picture. Next, however, his argument is that the formal definition of a concept is not of help in this learning. His opinion is that such formal mathematics will become too much for the students in the learning process. Such reading of the teaching situation is related to what Kümmerer calls a gentle approach to mathematics (Kümmerer, 2001), since figurative approaches are more user-friendly. However, the teacher admits that students' mathematical knowledge becomes fragmented when not discussing relations between concepts. The teacher followed up his argument in the interview by referring to mathematical methods as a main interest among the students: 
T: They [the students] are good at learning methods. And... often this implies that they only want to learn methods. I have been interrupted, when trying to teach how to derive a certain method, by statements like 'give us the recipe!'

This accentuates an instrumental learning strategy, indicating that the students focus on how to solve tasks to obtain a correct solution rather than gaining deeper understanding of how the processes and procedures are derived. The teacher reflected on causes for such preferences during the interview, lifting time constraints as an important factor:

T: It is a dilemma. I would very much like to do much more deductions, force them [the students] to put up all the steps in order to get things more organized. Because they are.. they struggle to see the connections since there are so many concepts that are new to them. Ehm... but then we are simply beaten by the time factor. So...

After the session where the second episode took place, I asked the teacher about his reply to the student who wanted to integrate $\sin ^{2} x$, and also on that occasion he put blame on time constraints. Time was notably an issue with him, and during the interview he substantiated his argument by comparing two parallel courses in linear algebra that he had taught in a previous year. One course had been a module in an engineering education, the other a module in a teacher education:

$\mathrm{T}$ : There is a huge difference between having linear algebra in a class of engineering students and a class of teacher students for instance. In the teacher education we have 30 - maybe 40 percent more time, and then you can go into much more depth.

The teacher points to the extensive content in the mathematics courses in engineering educations, not having allocated corresponding time to deal with all this content. Brandell and colleagues (Brandell, Hemmi, \& Thunberg, 2008) point to the overload of content in first year mathematics courses at the tertiary level, and the teacher's statement supports the idea that this is particularly problematic in engineering educations. His argument is that the course content in these educations are comprehensive compared to disposable time. If students are obliged to solve problems from an extensive course material but within short time limits, it may be tempting to apply readymade methods for solutions without seeking knowledge of deeper structures. When both the teacher and students experience the calculus course to have an extensive content, this may impel instrumental emphasises as these are perceived to be both easier to teach and learn (Khiat, 2010).

\section{Discussion}

The first research question in the paper asked what positive characteristics there are to some instrumental episodes observed among freshmen-engineering students in a mathematics classroom. The analysis of the events along with students' statement in interviews bear witness of a number of instrumental approaches taking place, both with S- and I-rationale for learning. They range from calculations - including repeated routines -, use of remedies and search for common rules, to avoidance of formalism and theory. All these approaches may be interpreted in somewhat negative terms, arguing that they mainly concern memorising and searching for recipes without understanding, with strive for oversimplification and less cognitive demanding solutions. Nevertheless, the analysis revealed positive aspects too. In the episodes, valuable lines of attack were initiatives to improve self-concept in mathematics, work to take advantage of available remedies and activities to search for relations between task approaches. Statements given in interviews with the students prolonged these arguments. The feeling of satisfaction with being able to master advanced calculations may increase self-confidence and seeking information in lecture notes to avoid struggling with too many unfamiliar symbols and formalism signalise a want to understand the mathematical approaches. Still, even if finding positive characteristics about such instrumental approaches, learners need to develop both relational and instrumental learning in mathematics (Rittle-Johnson et al., 2015). 
What may be the reasons why merely pure instrumental approaches then are preferred in the given situations? This question is linked to the second research question of the present paper, seeking explanations to the logged mathematical behaviours and opinions. Explanations were partly given in interviews with students - but perhaps mostly in interviews with the responsible teacher. A main concern with this teacher was precisely his experience of students' preference to learning methods. His statement about students wanting a recipe points to this, and the teacher blames limited time for mathematics in engineering educations to be a major problem. Courses in engineering mathematics are often overloaded with content, thus time constraints are experienced. This is a challenge in many first year mathematics courses at university (Brandell et al., 2008), but the responsible teacher stressed engineering educations to be particularly pressed. He substantiated his claim by comparing two similar linear algebra courses, one given to engineering students, the other to teacher students, claiming to have more time in the teacher education course. This argument may have various viewpoints; one being in what depth each concept in mathematics is discussed. Engineering educations should ideally have allocated time enough to treat concepts in a deeper manner. In in our country, however, these educations are strictly designed and framed by a national plan that decides the number of subjects required (UFD, 2011), subjects that often include laboratory activities. The plan is rather comprehensive, thus inevitably timetables in engineering educations are busy. A way to meet such pressure on time is to coordinate mathematics and professional subjects. Some degree of harmonization may lead to better exploitation of time but also generate common projects for better learning and use-value: "Engineers are required to study mathematics to develop application skills to enable them to solve engineering problems and to develop an attitude of mind expected of professional engineers. Transferable and knowledge-based skills as well as applications skills need to be developed" (McGregor \& Scott, 1995, p. 120). Such connections and motivations for mathematics are emphasised by researchers to be essential and give room for discussing how mathematics may serve an engineering education better (Cardella, 2008; Harris et al., 2015; Kümmerer, 2001). It improves the relevance of mathematics as being something more than a routine work (Steen, 2001), but presumes a close cooperation between all teachers involved in an engineering program. Such cooperation, however, may yield tensions as professionals may stress their own discipline to be more important than mathematics and vice-versa. Mustoe points to the difference in expectations as to which role mathematics has in engineering educations (Mustoe, 2002). A typical tension was revealed during discussions with a teacher in computer science at the university where the present research took place. His statement was: "The students are not going to be mathematicians, you know. Out there - in the real world - they will mainly deal with computational tools anyway". He points to an industry that often uses readymade computational tools. However, if not accompanied with mathematical reasoning, such tools can drive an instrumental learning where computers are used and solutions are retrieved unreflectively. Reed and collegues emphasize a need of taking several factors into account if mathematical computer tools are to promote learning (Reed, Drijvers, \& Kirschner, 2010). The most important factor is tool use embedded within meaningful mathematical discourse since this impel reflections and discussions of ideas with others.

Additional to the impact coordination of subjects in an engineering education may have on students' work with mathematics, a number of other features may influence. Issues like mathematical approaches stressed in lectures, textbook approaches and, perhaps most important, tasks formats of students' examinations have substantial impact.

When discussing plans for lectures with the teacher, he emphasized relational learning as connecting new concepts to figurative representations. He argued that engineering students understand, or in his words 'get into their head', these representations better. Such a view is supported by research, as engineering students often perceive and process information visually. This may for instance be in communication by digital visualization tools, paper-based representations and gestures (Hogstad, Isabwe, \& Vos, 2016), or apprehension by visual sensory information like pictures, diagrams and flow 
charts related to performance (Felder, 2005; Hames \& Baker, 2015). At the same time, however, the teacher argues that that formal definitions are not useful because this becomes too much for the students in the learning process. This statement adds to the interviewed students' opinions about formalism and theory being neither intelligible nor relevant to their learning of mathematics. A similar reluctance to formal mathematical arguments was discovered when analysing an engineering student's lecture notes (Rensaa, 2014). The student frequently added explanations to symbols occurring in the notes, using her own words to clarify the meaning. Pimm argue that students have problems in their decoding of symbols because they read the symbols themselves and not the meaning of them (Pimm, 1987).

Students' focus on instrumental understanding may also be commenced by what kind of tasks the textbook in a mathematics course offers - as tasks often guide students work with the subject. Randahl and Grevholm (2010) analyse the chapter dealing with the derivative in the textbook used in the present calculus course (Adams, 2006). Their analysis shows that $54 \%$ of the exercises are within the category 'Exercises which mainly require the use of particular procedures' while on the other side $20 \%$ are in the category 'Exercises in which justification of the solution is required or new context is used'. Problem is that most task sections follow a system of gradually increase in demands, starting with calculative tasks and ending with more advanced ones. This is positive in terms of building selfconfidence with students. Randahl's concern with such a system, however, is that students who struggles with mathematics use more time to accomplish the initial tasks. Thus, they rarely meet the advanced ones (Randahl, 2012). Then their problem-solving activities will mainly be instrumental.

A third, and probably most important influence on students' work in a mathematics course is assessment and signals that previous exam tasks send about what to expect in an upcoming exam. Such influences are shared by most disciplines. In the second episode, the student changed approach when getting to know that he would not be asked to provide an argument on how to integrate $\sin ^{2} x d x$ on the final exam. In the third episode, two students meant to have found commonalities in solution manuals to rate-of-change-tasks and searched for a common rule that they could use in the final exam. Vinner problematizes exactly this: the majority of students regard mathematics "as a collection of procedures to be used in order to solve some typical questions given in some crucial exams" (Vinner, 2007, p. 2). Students behave not only by relying on mathematical knowledge but also by adapting their knowledge to the milieu - the well-known 'didactical contract' by Brousseau (1997). Tasks given in previous exams play an essential role as representing a kind of contract with the students about what to put emphasis on. In the present calculus course, a rough categorizing of tasks in the previous four exam sets showed that 60-70 percent of the tasks were of an algorithmic type, where knowing a particular procedure would be enough to find a solution. This means that concentrating on instrumental approaches would be sufficient to preform rather well. Researchers have problematized that standard examinations in mathematics in engineering educations most commonly are of an instrumental character (Engelbrecht et al., 2012; Khiat, 2010), encouraging instrumental learning. Exam tasks ought to cover a broad aspect of mathematical competencies, and a tool for analysing competencies in tasks is suggested in (Rensaa, 2011).

In the context of the present research, social and educational elements outside the classroom may influence students' approaches to mathematics. An example of such a context influence is what Bergqvist calls traditions in mathematics educations at university level (Bergqvist, 2006). She shed light on the inheritance that freshmen-engineering students seem to take on from more experienced students, preparing them for the learning of algorithms in mathematics without time for reflection (Bergqvist, 2006). Thus, students have a predetermined expectation to meet similar approaches. Maull and Berry (2000) support this view, drawing on literature saying that engineering students are socialized into certain ways of thinking. This is about interactions with peers, lecturers and professional contacts, but is also about what is useful in the context of the students' study and 
work.When the teacher in the present study referred to the students that had interrupted his deductions with statements like 'give us the recipe', it illuminates a type of tradition where algorithms are preferred. Some engineering students strive for doing mathematics rather than studying mathematics. Kümmerer calls this the 'workman approach', in which following a set of rules will give the answer (Kümmerer, 2001). The wide range of social context elements that may influence engineering educations and students' approaches to mathematics is however out of range of the present investigation. It is a limitation of the research, but may serve as an objective in a future investigation.

\section{Conclusion}

The aim of the present paper has been to examine and search for explanations to three instrumental episodes logged in an engineering students' classroom. Instrumental approaches to mathematics are not unusual among engineering students, as pointed out by researchers (Engelbrecht et al., 2012; Khiat, 2010). The investigation has been somewhat biased since taking as a starting point a want to reveal positive characteristics about instrumental approaches and - to a large degree - not discuss the negative ones. However, when engineering students often pursue instrumental understanding, it is valuable to gain knowledge about what advantages such approaches may have. Thus, the present paper has deliberately focused on some instrumental episodes, illuminating strategies that often are referred to in somewhat negative tones. Students should not apply themselves to routine methods, should not use readymade formulas at the expense of knowing how to derive a solution and should not endeavour to find patterns from previous tasks in order to solve new ones. Mellin-Olsen problematize such approaches when discussing pupil's learning behaviour related to the educational context (Mellin-Olsen, 1981): "We see it in the case of instrumental learning - what is it in the pupil's idea of school which provides them with such learning strategies, when educators make every attempt to prevent such learning?" (Mellin-Olsen, 1981, p. 356). In line with this, the present episodes are 'unwanted'. Still, such approaches are not unusual, and the present paper has analysed the episodes in order to get insight into what is going on in such lines of attack and why students may prefer instrumental strategies. Interviews with students and the teacher revealed that instrumental approaches may originate from students' own preferences, but may also be a result of issues in the learning environment.

A conclusion from the present study is that different students are motivated for mathematics in different ways, and instrumental approaches may serve as a valuable approach to some. The paper has put focus on positive characteristic about such approaches, which is somewhat deviant compared to other research objects. Research has traditionally put attention on learning for relational understanding (Carpenter \& Lehrer, 1999). The present results highlight positive elements like building self-confidence, eagerness to find solutions, and taking advantage of provided material. Sometimes students' motivation for doing mathematics may be something else but open-ended, project based or investigative tasks. A long-serving mathematics teacher at the university where the research was accomplished put this into words: "Mathematics is like riding a bike. You need to practice, practice and more practice, and suddenly you realize what it is all about". According to this, practising methods both with and without use of tools, may nourish relational learning. The longserving teacher stress that students who get familiar with instrumental approaches may experience a feeling of succeed, leading to extend of interest to more than getting the correct answer. This again may stimulate a search as to why procedures work. If students are motivated by instrumental approaches, then utilizing positive aspects about them may be an important starting point in teaching. Awareness of this may provide useful in stimulating for relational learning based on instrumental profits.

Based on a review of empirical results about mathematics learning, Rittle-Johnson and colleagues conclude that the belief that instrumental knowledge is not supporting relational knowledge is a 
myth. Still, research most frequently emphasise relational knowledge to support instrumental knowledge and not the other way around. Investigation of how the ordering of teaching is influencing students' knowledge will need further inquiries.

\section{References}

Adams, R. A. (2006). Calculus - A complete course (6 ed.). Toronto: Pearson Addison Wesley.

Anthony, G. (2000). Factors influencing first-year students' success in mathematics. International Journal of Mathematical Education in Science and Technology, 31(1), 3-14.

Baroody, A. J., Feil, Y., \& Johnson, A. (2007). An alternative reconceptualization of procedural and conceptual knowledge. Journal for Research in Mathematics Education, 38(2), 115-131.

Bergqvist, E. (2006). University mathematics teachers' views on the required reasoning in calculus exams. In E. Bergqvist (Ed.), Mathematics and mathematics education; Two sides of the same coin [PhD Thesis]. Umeå, Sweden: Umeå University Sweden.

Bergsten, C. (2011). Why do students go to lectures? Paper presented at the Seventh Congress of the European Society for Research in Mathematics Education, Rzeszow, Poland. http://www.cerme7.univ.rzeszow.pl/WG/14/CERME7-WG14Paper---Bergsten-REVISED-Dec2010..pdf

Blomhøj, M., \& Jensen, T. H. (2003). Developing mathematical modelling competence: Conceptual clarification and educational planning. Teaching Mathematics and its Applications, 22(3), 123-139.

Brandell, G., Hemmi, K., \& Thunberg, H. (2008). The widening gap - A Swedish perspective. Mathematics Education Research Journal, 20(2), 38-56.

Brousseau, G. (1997). Theory of Didactical situations in mathematics (Vol. 19): Kluwer Academic Publishers.

Bryman, A. (2004). Social research methods. Oxford: Oxford University Press.

Cardella, M. (2008). Which mathematics should we teach engineering students? An empirically grounded case for a broad notion of mathematical thinking. Teaching Mathematics and its Applications, 27(3), 150-159.

Carpenter, T. P., \& Lehrer, R. (1999). Teaching and learning mathematics with understanding. In E. Fennema \& T. A. Romberg (Eds.), Mathematics Classrooms That Promote Understanding (pp. 19-32). Mahwah, NJ: Lawrence Erlbaum Associates.

Engelbrecht, J., Bergsten, C., \& Kågesten, O. (2012). Conceptual and Procedural Approaches to Mathematics in the Engineering Curriculum: Student Conceptions and Performance. Journal of Engineering Education, 101(1), 138-162.

Felder, R. M., \& Brent, R. (2005). Understanding Student Differences. Journal of engineering education, 94(1), 57-72.

Gallagher, D. J. (1995). In search for the rightful role of method: reflections on conducting a qualitative dissertation. In T. Tiller, A. Sparkes, S. Kårhus, \& F. Dowling Næss (Eds.), The Qualitative Challenge: Reflections on Educational Research (pp. 17-35). Landsås, Norway: Caspar Forlag.

Hames, E., \& Baker, M. (2015). A study of the relationship between learning styles and cognitive abilities in engineering students European Journal of Engineering Education, 40(2), 167-185.

Harris, D., Black, L., Hernandez-Martinez, P., Pepin, B., \& Williams, J. (2015). Mathematics and its value for engineering students: what are the implications for teaching? International Journal of Mathematical Education in Science and Technology, 46(3), 321-336.

Hiebert, J. (1986). Conceptual and procedural knowledge: The case of mathematics. Hillesdale, NJ: Erlbaum.

Hiebert, J., \& Lefevre, P. (1986). Conceptual and procedural knowledge in mathematics: An introductory analysis. In J. Hiebert (Ed.), Conceptual and procedural knowledge: The case of mathematics (pp. 1-27). Hillesdale, NJ: Erlbaum.

Hogstad, N. M., Isabwe, G. M. N., \& Vos, P. (2016). Engineering students' use of visualizations to communicate about representations and applications in a technological environment. Paper presented at the International Network for Didactic Research in University Mathematics, INDRUM 2016 Montpellier. https://hal.archivesouvertes.fr/INDRUM2016/public/indrum2016proceedings.pdf

Jaworski, B. (1994). Investigating Mathematics Teaching: a Constructivist Enquiry. London ; Washington, D.C.: Falmer Press.

Kashefi, H., Ismail, Z., \& Yusof, Y. M. (2012). Engineering mathematics obstacles and improvements:a comparative sudy of students and lectureres perspectives through creative problem solving. Procedia - Social and Behavioral Sciences, 56, 556564.

Khiat, H. (2010). A grounded theory approach: Conceptions of understanding in engineering mathematics learning. The Qualitative Report, 15(6), 1459-1488.

Kümmerer, B. (2001). Trying the impossible: Teaching mathematics to physicists and engineers. In D. Holton (Ed.), The teaching and learning of mathematics at university level: An ICMI study (pp. 321-334). Dordrecht: Kluwer Academic Publishers.

Mason, J. (1998). Researching from the inside in mathematics education. In A. Sierpinska \& J. Kilpatrick (Eds.), Mathematics Education as a Research Domain: A Search for Identity (Vol. 4, pp. 357-377). London: Kluwer Academic Publishers.

Maull, W., \& Berry, J. (2000). A questionnaire to elicit the mathematical concept images of engineering students. International Journal of Mathematical Education in Science and Technology, 31(6), 899-917.

McGregor, R., \& Scott, B. (1995). A View on Applicable Mathematics Courses for Engineers. In L. Mustoe \& S. Hibberd (Eds.), Mathematical Education of Engineers (pp. 115-129). Oxford: Clarendon Press.

Mellin-Olsen, S. (1981). Instrumentalism as an educational concept. Educational Studies in Mathematics, 12, 351-367.

Mustoe, L. (2002). Mathematics in engineering education. European Journal of Engineering Education, 27(3), 237-240. 
Piaget, J., \& Inhelder, B. (1969). The psychology of the child. London: Routledge \& Kegan Paul.

Pimm, D. (1987). Speaking mathematically: Communication in mathematics classrooms. New York: Routledge and Kegan Paul.

Randahl, M. (2012). First-year engineering students' use of their mathematics textbook - opportunities and constraints. Mathematics Education Research Journal, 24(3), 239-256.

Randahl, M., \& Grevholm, B. (2010). Learning opportunities offered by a classical calculus textbook. Nordic Studies in Mathematics Education, 15(2), 5-27.

Reed, H. C., Drijvers, P., \& Kirschner, P. A. (2010). Effects of attitudes and behaviours on learning mathematics with computer tools. Computers \& Education, 55(1), 1-15.

Rensaa, R. J. (2011). A task based two-dimensional view of mathematical competency used to analyse a modelling task. International Journal of Innovation in Science and Mathematics Education, 19(2), 37-50.

Rensaa, R. J. (2014). The impact of lecture notes on an engineering student's understanding of mathematical concepts. Journal of Mathematical Behavior, 34, 33-57.

Rensaa, R. J., \& Vos, P. (2017). Interpreting teaching for conceptual and for procedural knowledge in a teaching video about linear algebra. Paper presented at the Norma 17, Stockholm, Sweden.

Rittle-Johnson, B., Schneider, M., \& Star, J. R. (2015). Not a one-way street: Bidirectional relations between procedural and conceptual knowledge of mathematics. Educational Psychology Review, 27, 587-597.

Sazhin, S. S. (1998). Teaching mathematics to engineering students. International Journal of Engineering Education, 14(2), 145-152.

Skemp, R. R. (1978). Relational inderstanding and instrumental understanding. The Arithmetic Teacher, 26(3), 9-15.

Skemp, R. R. (1979a). Goals of Learning and Qualities of Understanding. Mathematics Teaching, 88, 44-49.

Skemp, R. R. (1979b). Intelligence, learning, and action : a foundation for theory and practice in education. Chichester: Wiley.

Skemp, R. R. (1987). The psycology of learning mathematics. London: Penguin Books.

Stake, R. E. (1995). The Art Of Case Study Research: Sage Publications, Inc.

Steen, L. A. (2001). Revolution of stealth: Redefining university mathematics. In D. Holton (Ed.), The teaching and learning of Mathematics at university level (pp. 303-312). Dordrecht: Kluwer Academic Publishers.

UFD. (2011). Forskrift om rammeplan for ingeniørutdanning. Ministry of Education and Research.

Varsavsky, C. (1995). The design of mathematics curriculum for engineers: A joint venture of the mathematics department and the engineering faculty. European Journal of Engineering Education, 20(3), 341-345.

Varsavsky, C. (2010). Chances of success in and engagement with mathematics for students who enter university with a weak mathematics background. International Journal of Mathematical Education in Science and Technology, 41(8), 1037-1049.

Vinner, S. (2007). Mathematics education: Procedures, rituals and man's search for meaning. Journal of Mathematical Behavior, 26, $1-10$.

Wedege, T. (1999). To know or not to know - mathematics, that is a question of context. Educational Studies in Mathematics, 39, 205-227. 


\section{Appendix 1:}

Copy of the suggested solution of the task in Episode 1, provided by the responsible teacher:

$$
\begin{aligned}
& \arccos x+\frac{\pi}{6}=\arctan 2 \\
& \cos (\arccos x)=\cos (\underbrace{\arctan 2}_{=u}-\frac{\pi}{6}) \\
& x=\cos \left(u-\frac{\pi}{6}\right)=\cos u \cdot \cos \frac{\pi}{6}+\sin u \cdot \sin \frac{\pi}{6} \\
& x=\frac{\sqrt{3}}{2} \cos u+\frac{1}{2} \sin u \\
& x=\frac{\sqrt{3}}{2} \cdot \frac{1}{\sqrt{5}}+\frac{1}{2} \cdot \frac{2}{\sqrt{5}}=\frac{\sqrt{3}+2}{2 \sqrt{5}} \cdot \frac{\sqrt{5}}{\sqrt{5}}=\frac{\sqrt{15}+2 \sqrt{5}}{10}
\end{aligned}
$$

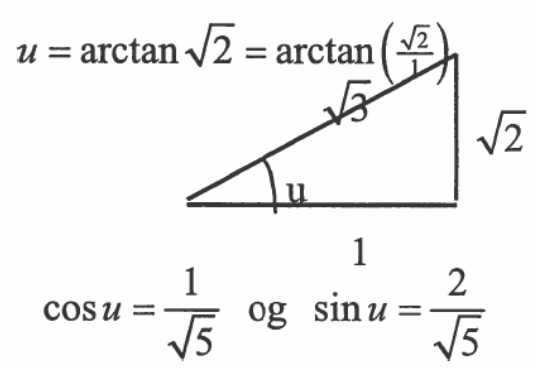

